\title{
Rejeição corneana pós transplante de córnea: análise de dados do Banco de Olhos do Hospital São Paulo - Escola Paulista de Medicina
}

\author{
Corneal graft rejection after penetrating keratoplasty: analysis of the Eye Bank of the \\ Hospital São Paulo - Escola Paulista de Medicina
}

Maria Regina Catai Chalita (1)

Eileen Beatriz Mejia Diazgranados ${ }^{(2)}$

Elcio H. Sato ${ }^{(3)}$

Bruno Castelo Branco ${ }^{(1)}$

Denise de Freitas ${ }^{(4)}$
Departamento de Oftalmologia da UNIFESP-EPM. Banco de Olhos do Hospital São Paulo.

Residente de terceiro ano, Oftalmologia UNIFESPEPM

(2) Residente de segundo ano, Oftalmologia UNIFESPEPM

Diretor médico do Banco de Olhos do Hospital São Paulo- UNIFESP- EPM

(4) Chefe do setor de Doenças Externas Oculares e Córnea do Departamento de Oftalmologia UNIFESP- EPM.

Endereço para correspondência: Maria Regina Catai Chalita. Rua Enrico de Martino, 500. São Paulo (SP) CEP 05652-010. e-mail: mariaregina@sti.com.br

\begin{tabular}{|c|}
\hline RESUMO \\
\hline $\begin{array}{l}\text { Objetivo: Dentre todos os transplantes, o corneano tem sido o mais } \\
\text { realizado na atualidade. Geralmente é bem sucedido, mas a rejeição } \\
\text { do enxerto corneano pode ser uma complicação. A rejeição é estuda- } \\
\text { da há muitos anos, já tendo sido estabelecidos alguns fatores } \\
\text { predisponentes. Este estudo tem como objetivo analisar os casos de } \\
\text { rejeição ocorridos em nosso serviço para detectar algum fator pecu- } \\
\text { liar para a ocorrência da mesma. } \\
\text { Métodos: Realizamos um estudo retrospectivo analisando } 113 \text { casos } \\
\text { de transplante de córnea ópticos efetuados no ano de } 1998 \text {. Destes, } \\
\text { selecionamos todos os casos de rejeição e avaliamos a patologia de base, } \\
\text { presença de sinéquias, neovasos, aumento da pressão intra-ocular, } \\
\text { antecedente de transplante prévio, idade do doador, tempo de captação } \\
\text { e de preservação da córnea, experiência do cirurgião. } \\
\text { Resultados: Dos } 113 \text { transplantes realizados, } 20 \text { casos (17,69\%) apre- } \\
\text { sentavam rejeição do botão transplantado. Destes } 20 \text { casos, } 9 \text { apresenta- } \\
\text { vam sinéquias, } 4 \text { tinham neovasos, } 8 \text { apresentaram aumento da pressão } \\
\text { intra-ocular e } 7 \text { já haviam se submetido a transplante de córnea prévio. } \\
\text { Conclusioes: Encontramos em nosso trabalho uma maior incidência } \\
\text { de rejeição nos casos em que havia fatores predisponentes. Aparente- } \\
\text { mente houve mais rejeições quando os cirurgiões eram inexperientes. } \\
\text { Também deve ser considerado o fato de sermos um serviço terciário, o } \\
\text { qual recebe casos mais complexos e com maior chance de complicações. }\end{array}$ \\
\hline
\end{tabular}

\section{INTRODUÇÃO}

O transplante de córnea é o procedimento de maior sucesso entre os transplantes teciduais em humanos e tem sido o mais realizado na atualidade. Está indicado para restaurar a transparência corneana, dar suporte tectônico, como auxílio diagnóstico e ou terapêutico. O transplante de córnea é geralmente bem sucedido, mas em alguns casos pode evoluir para rejeição do enxerto corneano ${ }^{1,2}$. Com a melhoria da técnica cirúrgica e com o aumento do número de drogas para tratamento da rejeição corneana ${ }^{3}$, a porcentagem de sucesso tem aumentado.

A rejeição em transplante de córnea ocorre pelo reconhecimento e sensibilização do hospedeiro ao doador ${ }^{4,5}$. A rejeição pode ser epitelial, estromal, endotelial ou ocorrer nas três áreas juntamente ${ }^{6}$. 
O diagnóstico de rejeição é cogitado quando o edema do enxerto ocorre após duas semanas de cirurgia, período este mínimo para reconhecimento do antígeno e desencadeamento do processo de rejeição ${ }^{7}$. Diferenciamos os casos de rejeição e falência primária pela presença de edema que não clareia por um período pós operatório longo (mais do que 14 dias) nos casos de falência.

Vários estudos foram realizados para identificar os fatores predisponentes da rejeição em transplante de córnea ${ }^{8,9}$. Vascularização corneana, o transplante prévio, o glaucoma e a idade do doador são fatores de risco importantes descritos ${ }^{10,11}$. Dentre os fatores predisponentes de rejeição, os mais citados são a vascularização corneana ${ }^{12}$, o diâmetro do botão transplantado (quanto maior, mais próximo dos vasos limbares e maior a chance de rejeição) ${ }^{13}$, a existência de um transplante prévio, a experiência do cirurgião, a idade do paciente doador da córnea, o aumento da pressão intra-ocular no pós-operatório, e a existência de sinéquias ${ }^{14}$. No Brasil não há estudos avaliando os fatores que levam à rejeição corneana e, para isso, analisamos os casos de rejeição corneana que ocorreram nos transplantes ópticos realizados em nosso Serviço, com a intenção de identificar os fatores peculiares de risco.

\section{MATERIAIS E MÉTODOS}

Durante o ano de 1998 foram realizados 113 transplantes ópticos eletivos pelas equipes de Córnea e Banco de Olhos do Departamento de Oftalmologia da UNIFESP-EPM. Não foram incluídos os casos tectônicos e diagnósticos. Destes, foram analisados retrospectivamente os prontuários com casos de rejeição do botão transplantado quanto: [1] tipo de patologia de base , [2] tempo de aparecimento da rejeição, [3] fatores predisponentes (sinéquias, neovasos), [4] aumento da pressão intra-ocular (Po) no pós operatório, [5] transplantes de córnea prévios e [6] experiência do cirurgião. Também foi avaliado o mês de ocorrência, com o objetivo de identificar os casos realizados por cirurgiões principiantes, uma vez que os residentes de terceiro ano e estagiários de primeiro semestre iniciam suas cirurgias no mês de janeiro e os estagiários de segundo semestre no mês de junho.

Quanto à córnea utilizada, analisamos a idade do doador, o tempo de captação (definido como tempo entre óbito e enucleação), e o tempo de preservação da córnea (definido como tempo entre preservação em meio e utilização na cirurgia).

Os pacientes foram examinados semanalmente nos dois primeiros meses pós- operatórios, sendo depois o retorno quinzenal até o terceiro mês, e mensal após este, com mudanças nessa agenda conforme a detecção de complicações. A medicação pós operatória preconizada em nosso Serviço é acetato de prednisolona $1 \%$ colírio $2 / 2$ horas; ofloxacina colírio $4 \mathrm{x}$ ao dia, com diminuição gradativa conforme cada evolução.

\section{RESULTADOS}

Dos 113 transplantes de córnea analisados, 20 casos $(17,69 \%)$ apresentaram rejeição do botão transplantado.
Houve um aumento na porcentagem de casos de rejeição durante os meses de Janeiro e Fevereiro, bem como de Junho e Julho (Gráfico 1). Ressaltamos que o número de transplantes realizados em cada mês foi muito parecido, com exceção do mês de Outubro (Tabela 1).

Em relação à patologia de base, $4(20 \%)$ eram pacientes com ceratocone; 3 (15\%) ceratopatia bolhosa do pseudofácico; $3(15 \%)$ leucoma pós infecção herpética; $2(10 \%)$ leucoma pós trauma; 2 (10\%) distrofia de Fuchs; 2 (10\%) leucoma pós úlcera. Havia 1 caso $(5 \%)$ de ceratite intersticial, 1 caso $(5 \%)$ de leucoma pós queimadura, 1 caso $(5 \%)$ de leucoma pós tracoma e 1 caso (5\%) de doença de Fabry (Tabela 2).

Quanto a fatores predisponentes conhecidos, observamos $9(45 \%)$ com sinéquias, 4 (20\%) com neovasos e $8(40 \%)$ com aumento da Po.

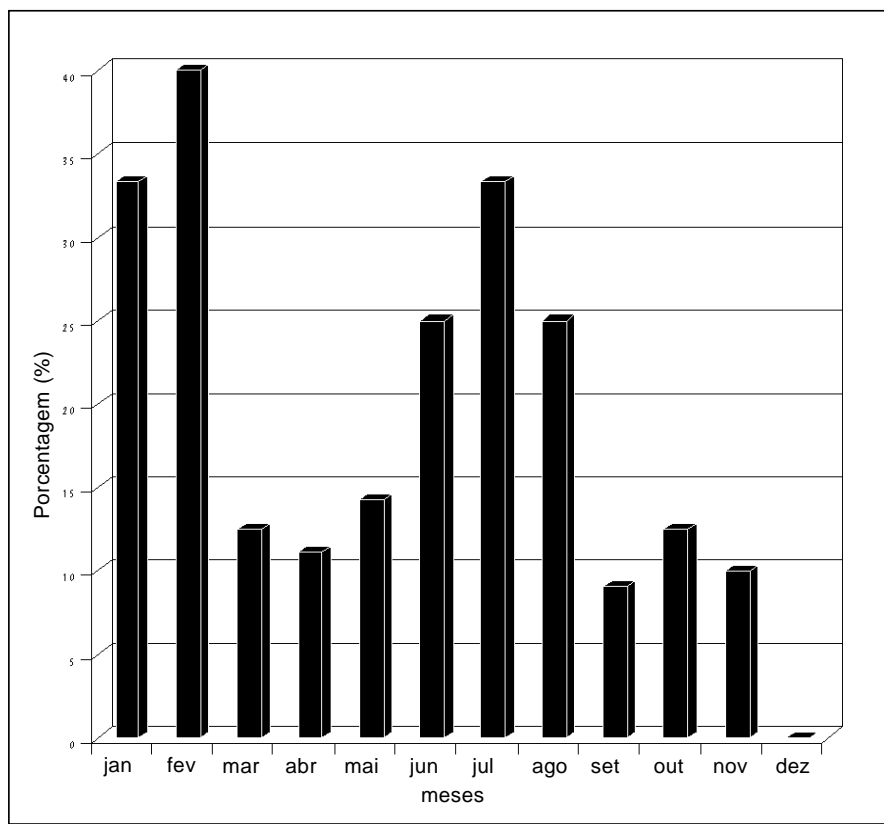

Gráfico 1 - Porcentagem de Rejeição de Transplante nos meses de 1998

Tabela 1

\begin{tabular}{lcc} 
Meses de 1998 & $\mathbf{N}^{\circ}$ de transplantes & $\mathbf{N}^{\circ}$ de rejeições \\
Janeiro & 9 & $3(33,33 \%)$ \\
Fevereiro & 10 & $4(40,00 \%)$ \\
Março & 8 & $1(12,50 \%)$ \\
Abril & 9 & $1(11,11 \%)$ \\
Maio & 7 & $1(14,28 \%)$ \\
Junho & 8 & $2(25,00 \%)$ \\
Julho & 6 & $2(33,33 \%)$ \\
Agosto & 8 & $2(25,00 \%)$ \\
Setembro & 11 & $1(9,09 \%)$ \\
Outubro & 16 & $2(12,50 \%)$ \\
Novembro & 10 & $1(10,00 \%)$ \\
Dezembro & 11 & $0(0 \%)$ \\
Total & 113 & $20(100 \%)$ \\
\hline
\end{tabular}




\begin{tabular}{|lcc|}
\hline & Tabela 2 & \\
Patologia de base & $\mathbf{N}^{\circ}$ de casos & $(\%)$ \\
Ceratocone & 4 & $20 \%$ \\
Ceratopatia bolhosa & 3 & $15 \%$ \\
Leucoma pós herpes & 3 & $15 \%$ \\
Leucoma pós trauma & 2 & $10 \%$ \\
Distrofia de Fuchs & 2 & $10 \%$ \\
Leucoma pós úlcera & 2 & $10 \%$ \\
Ceratite intersticial & 1 & $5 \%$ \\
Leucoma pós queimadura & 1 & $5 \%$ \\
Leucoma pós tracoma & 1 & $5 \%$ \\
Doença de Fabry & 1 & $5 \%$ \\
Total & 20 & $100 \%$ \\
\hline
\end{tabular}

Transplante prévio foi realizado em 7 pacientes (35\%).

A córnea doadora tinha, em média, 44,75 anos (variando de 3 a 86 anos). A média de tempo de preservação foi de 6,75 dias (variando de 1 a 14 dias). A média de tempo de captação foi de 4,2 horas (variando de 30 minutos a 18 horas e 30 minutos).

\section{DISCUSSÃO}

Em nosso estudo obtivemos uma taxa total de rejeição em 1998 de 17,69\% (20 em 113 casos de transplante), maior que a encontrada nos estudos de Price e cols., que encontrou uma taxa de $6,1 \%$, assim como Vail e cols., que encontraram taxa de $12 \%{ }^{10,14}$. Creditamos isto ao fato de que nosso serviço é um hospital-escola, onde os cirurgiões são residentes do terceiro ano de oftalmologia e estagiários no primeiro ano de estágio no setor, com experiência limitada. É importante também considerar que, por ser um Serviço terciário, os casos mais complexos e de prognóstico mais reservado são encaminhados a estes serviços, ponto este que poderia contribuir para a existência de uma taxa maior de rejeição.

Com relação à existência de sinéquias, que denotam um processo inflamatório, estas estavam em 9 dos 20 casos estudados (45\%), mostrando ser um fator predisponente. Na literatura encontramos vários trabalhos mostrando esta relação entre a inflamação e a rejeição ${ }^{8,10}$.

A existência de um transplante prévio ocorreu em 35\% dos casos estudados. Este número significativo de pacientes com transplantes prévios deve-se, provavelmente, ao fato de recebermos casos mais complicados e é comprovado pelo estudo de Shapiro e cols. que encontraram um risco de rejeição de 40 a $60 \%$ dos casos quando há transplante prévio ${ }^{7}$.

$\mathrm{O}$ aumento da pressão intra-ocular também foi um achado em nosso estudo como fator predisponente, ocorrendo em 40\% dos casos. Vail e cols., em seu trabalho em 1997 também verificaram esta correlação ${ }^{14}$.

Os neovasos aparecem em $20 \%$ em nossos casos que evoluíram com rejeição, sendo também um fator predisponente que devemos levar em consideração, como o observado em vários trabalhos ${ }^{8,10,14}$.
A idade média dos pacientes doadores das córneas foi de 44,75 anos (3-86 anos), sendo esta média adequada para a obtenção de uma boa córnea para transplante ${ }^{15}$. As médias de tempo de captação da córnea (4,2 horas) e de tempo de preservação da córnea (6,75 dias) também encontraram-se dentro dos limites preconizados pelos Bancos de Olhos existentes (captar córneas até 6 horas pós-óbito e usar córneas preservadas por no máximo 14 dias) ${ }^{15}$.

Um fator importante que devemos notar neste estudo é que o número de rejeições nos últimos meses do ano estudado é bem pequeno (por exemplo, nenhuma rejeição em dezembro). Isto pode ser creditado ao fato de o tempo de acompanhamento ter sido maior nos pacientes operados no início do ano, e os operados no final do ano ainda poderão vir a apresentar uma rejeição tardia. Para sanar este fator, estudos com um acompanhamento mais prolongado já estão em andamento.

É muito importante que o cirurgião identifique previamente os fatores de risco presentes para a rejeição em cada caso a ser operado para que se classifique se é um caso de baixo risco ou de alto risco para rejeição. O oftalmologista deve estar atento a qualquer sinal inflamatório e sempre suspeitar de rejeição, principalmente nos casos de alto risco ${ }^{16}$.

\section{CONCLUSÃO}

Muitos fatores devem ser rigorosamente averiguados antes de submetermos o paciente a um transplante de córnea. Se houver história de transplante prévio, sinéquias, neovasos ou aumento da pressão intra-ocular no pós-operatório, estes pacientes devem ser orientados e seguidos com maior freqüência com o intuito de diagnosticarmos precocemente uma possível rejeição, e deste modo aumentar as chances de sucesso do transplante.

Outro ponto importante a ser lembrado é que uma maior atenção deve-se ter em serviços universitários, por serem serviços referenciais e porque os oftalmologistas em treinamento têm menor experiência, realizam cirurgias mais demoradas, com maior trauma ao tecido.

\section{SUMMARY}

Purpose: Among all grafts, corneal transplantation is the most commonly performed. Graft outcome is usually good, but some cases failure due to rejection can be observed.There are some well-known risk factors for corneal graft rejection. The purpose of this study is to analyze cases of corneal graft rejection in our Service focusing on peculiar risk factors.

Methods: We analyzed 113 cases of penetrating keratoplasties performed in 1998. Cases of corneal graft rejection were evaluated in relation to preoperative diagnosis, existence of synechia, corneal vascularization, increased intraocular pressure, previous graft rejection, donor age, time of enucleation and preservation of the donor cornea and the surgeon's surgical experience. 
Results: We were able to identify 20 (17.69\%) cases of graft rejection. Among these 9 had synechia, 4 corneal neovascularization, 8 increased intraocular pressure and 7 previous graft rejection.

Conclusions: Our results are in agreement with those of the literature. It seems that the surgeon's experience plays a role in corneal graft rejection. It is important to call attention to the fact that reference services handle difficult and more complicated cases which may be at a higher risk to rejection.

Keywords: Corneal transplantation; Rejection; Eye banking; Ocular surgery.

\section{REFERÊNCIAS BIBLIOGRÁFICAS}

1. Coster DJ, Williams KA. Transplantation of the cornea. Med J Aust 1992;157(6):405-8

2. Pecego JG, Buxton JN, Schuman M. Reação imunológica ao transplante de córnea após ceratoplastia penetrante unilateral e bilateral em ceratocone. Arq Bras Oftalmol 1981;44(6):199-201.

3. Hayashi S, Belfort Jr R. Subconjunctival methotrexate in the treatment of non infectious ocular inflamatory diseases. Arq Bras Oftalmol 1997;60(3):303-6.
4. Paufique L, Sourdille P, Offret G. Les greffes del la cornee, Paris, 1948 , Masson et Cie apud Foulks G.N., 1996; p. 1687-96.

5. Maumenee AE. The influence of donor-recipient sensitization on corneal grafts. Am J Ophthalmol 1951;34:142-52.

6. Khodadoust AA, Silverstein AM. Transplantation and rejection of individual cell layers of the cornea. Invest Ophthalmol Vis Sci 1969;8:180-95.

7. Shapiro MB, Mandel MR, Krachmer JH. Rejection- clinical forms, diagnosis, and treatment. In: Brightbill FS, eds. Corneal Surgery- Theory, technique and tissue. Mosby, second edition 1993;254-68.

8. Arentsen JJ. Corneal transplant allograft reaction: possible predisposing factors. Trans Am Ophthalmol Soc 1983;81:361-402.

9. Bocacio FJ Transplante de córnea: análise do presente e perspectiva para o futuro. An Oftalmol 1990;9(1):138-9.

10. Price Jr FW, Whitson WE, Johns S, Gonzales JS. Risk factors for corneal graft failure. J Refract Surg 1996;12:134-47.

11. Alldredge OC, Krachmer JH. Clinical types of corneal transplant rejection: their manifestations, frequency, preoperative correlates and treatment. Arch Ophthalmol 1981;99:599-604.

12. Friedland MH. Corneal allograft rejection. Refract Corneal Surg 1991;7(1):70-2

13. Cherry PMH, Pashby YRC, Tadros ML, Wolf BA, Chipman ML. An analysis of corneal transplantation, I eye - graft clarity. Ann Ophthalmol 1979;11(3):461-9.

14. Vail A, Gore SM, Bradley BM, Easty DL, Rogers CA, Armitage WI. Conclusions of the corneal transplant follow up study. $\mathrm{Br} \mathrm{J}$ Ophthalmol 1997:81:631-6.

15. Lottenberg CL, Belfort Jr R. Banco de olhos. In Belfort Jr R, Kara Jose N. Córnea clínica e cirúrgica. Primeira edição, 1997; 463-469.

16. Foulks GN. Clinical aspects of corneal allograft rejection. In Krachmer JH, Mannis MJ, Holland EJ. Cornea. Mosby-First edition 1997;1687-96.

\section{Comentário do artigo:}

\section{"Rejeição corneana pós transplante de córnea - análise de dados do Banco de Olhos do Hospital São Paulo - Escola Paulista de Medicina"}

\section{Odair Guimarães}

Ao ser solicitado pelo Conselho Editorial dos Arquivos Brasileiros de Oftalmologia para comentar o trabalho escrito pelos eminentes colegas da Escola Paulista de Medicina intitulado "Rejeição corneana pós transplante de córnea análise de dados do Banco de Olhos do Hospital São Paulo Escola Paulista de Medicina", é para mim uma enorme responsabilidade, conhecendo a estirpe de seus autores. Acreditamos que esta nova norma adotada pelos "Arquivos" enriquecerá ainda mais os seus leitores com tais comentários e

Presidente do Banco de Olhos de Minas Gerais

Chefe do Serviço de Córnea do Hospital Felicio Roxo os autores ficarão mais tranquilos de acordo com a visão crítica do revisor que é considerado "demônio aborrecedor e destrutivo", como disse o Prof. Bicas em um de seus editoriais. Este trabalho é de grande valia, não somente para os profissionais que trabalham na área de transplante de córnea, como também para aquelas pessoas envolvidas na coleta de córnea. Trata-se de estudo retrospectivo bem estruturado da rejeição do transplante de córnea, que é o pavor dos cirurgiões. A metodologia é bem delineada. O cuidado com o resultado e discussão são colocados de forma minuciosa e coerente. Apresenta uma bibliografia vasta e recente. É uma publicação singular e de grande valor no meio científico Brasileiro.

\section{Novidades na Internet:!!}

\section{Agora no site CBO você tem disponível todas as informações na íntegra dos}

Arquivos Brasileiros de Ditalmologia

http://www.cho.com.br/abo 